\title{
Sutureless Glue Free Versus Sutured Limbal Conjunctival Autografts In Primary Pterygium Surgery
}

\author{
Dikshya Bista $^{1(\mathbb{0})}$, Raghunandan Byanju $^{2(2)}$, Maria Alexsandronva Gautam ${ }^{2(20}$ \\ ${ }^{1}$ Geta Eye Hospital, Geta, Kailali, Nepal \\ ${ }^{2}$ Bharatpur Eye Hospital, Bharatpur, Chitwan, Nepal
}

\begin{abstract}
Introduction: Surgical excision is the definitive treatment for pterygium. Following excision, conjunctival autograft is usually preferred. Various methods for grafting with sutures, glue or autologous serum from the recipient bed are in use. The objective of this study was to compare surgical outcomes of sutureless glue free conjunctival autograft with sutured (vicryl 8-0) conjunctival autograft in primary pterygium excision.
\end{abstract}

Materials and methods: A prospective randomized interventional study was carried out in 100 eyes with primary pterygium. They were divided into two groups for conjunctival graft adhesion; sutureless glue free (group 1; $\mathrm{n}=50$ eyes) and sutured with absorbable (vicryl 8-0) suture (group 2; $\mathrm{n}=50$ eyes). Time taken for surgery, complications, postoperative symptoms and overall satisfaction score were noted. The patients were followed up on day 1, day 14 and 6 weeks after surgery. Recurrence was noted till 1 year after surgery.

Results: The mean age was $46.76 \pm 11.97$ years (group 1) and $47.24 \pm 12.76$ years (group 2). Group 1 had shorter duration of surgery $(p<0.001)$, less postoperative complaints $(p<0.001)$ and better patient satisfaction $(p<0.001)$ than group 2. Postoperative complications and gain in visual acuity in both the groups were not clinically significant. Recurrence was not significant in both groups until 1 year of follow up.

Conclusion: Pterygium surgery with sutureless glue free conjunctival autograft had fewer postoperative complaints and better patient satisfaction than pterygium surgery with sutured conjunctival autograft. The postoperative complications, recurrence were comparable to conventional sutured technique.

Key words: Fibrin glue, Glue-free pterygium surgery, Pterygium, Recurrence, Sutureless glue free conjunctival autograft.

$\begin{array}{ll}\text { Financial Interest : Nil } & \text { Received : 20.09.2020 } \\ \text { Conflict of Interest : Nil } & \text { Accepted : 06.03.2021 } \\ \text { Corresponding Author } & \\ \text { Dr. Dikshya Bista } & \\ \text { Geta Eye Hospital, } & \\ \text { Geta, Kailali, Nepal. } & \\ \text { E-mail: dr.dikshya12@gmail.com } & \end{array}$

Access this article online

Website: www.nepjol.info/index.php/NEPJOPH DOI: https://doi.org/10.3126/nepjoph.v13i2.31347 Copyright $\odot 2021$ Nepal Ophthalmic Society ISSN: 2072-6805, E-ISSN: 2091-0320

This work is licensed under a Creative Commons Attribution-NonCommercial-NoDerivatives 4.0 International License (CC BY-NC-ND). 


\section{INTRODUCTION}

Pterygium is a fibrovascular proliferation of subconjunctival tissue towards the cornea which is more common on the nasal side. It is thought to be caused by ultraviolet rays, hot dry climate, dust, wind (Hill and Maske, 1989). Surgical excision is the treatment of choice for pterygium.

Simple surgical excision technique leaving bare sclera is not favored due to high recurrence rates (Youngson, 1972). Recurrences occur mostly within a year of surgery (Avisar et al., 2001; Hirst et al., 1994). Several techniques like beta irradiation, Mitomycin C, amniotic membrane transplantation have been tried to reduce the recurrence rate (Kawasaki et al., 2003; Lam et al., 1998; Monselise et al., 1984).

Conjunctival autograft with limbal to limbal orientation reduces the chances of recurrence as stem cells in the limbus act as a barrier for conjunctival cells (Salman and Mansour, 2011) . The autograft could be held at the graft site by sutures, fibrin glue or autologous fibrin from the graft recipient site.

Sutureless techniques either with fibrin glue or autologous fibrin have shown to be comfortable postoperatively (Elwan, 2014; Yan et al., 2019; Yüksel et al., 2010). It is said to have lesser complications, shorter surgery time and reduced rate of recurrence (Koranyi et al., 2005, 2004).

The cost of the fibrin glue has been a limiting factor for its use (Yüksel et al., 2010). A better alternative for it would be letting fibrin at the recipient bed to hold the graft as in a sutureless and glue-free technique.
In this study, both techniques were compared in terms of operative time, complications, postoperative symptoms, overall satisfaction and recurrence. Sutureless technique can be a better alternative if patients have similar postoperative results with less discomfort.

\section{MATERIALS AND METHODS}

Hundred eyes of 100 patients were randomised into two groups; either sutureless and glue free autograft (group 1; $n=50$ eyes), or sutured absorbable (vicryl 8-0) autograft (group 2; $\mathrm{n}=50$ eyes) technique of autograft adhesion. All patients underwent surgery under local anaesthesia by a single surgeon and were followed up on day 1, day 14, 6 weeks after surgery. Recurrence was observed until 1 year after surgery. During follow up, visual acuity, complaints of patients and any complications related to surgery were noted.

Peribulbar anesthesia with $2 \%$ lignocaine and $0.5 \%$ bupivacaine was given preoperatively. An eyelid speculum was inserted. The body of the pterygium was excised around $4 \mathrm{~mm}$ from the limbus and it was removed by avulsion. The head of the pterygium was detached using a crescent knife. The body was dissected from the overlying conjunctiva using blunt and sharp dissection. The subconjunctival pterygium tissue, the thickened segment of conjunctiva and adjacent Tenon's capsule were excised leaving bare sclera. Size of the bare sclera was measured with callipers. Conjunctival autograft was taken from the superior quadrant after giving subconjunctival injection lidocaine which facilitates separation of conjunctiva from Tenon's capsule. The conjunctiva was dissected, 
around $2 \mathrm{~mm}$ more than the size measured at the recipient bed, by Westcott's scissors. It was then separated upto the limbus and cut. Forceps was used to slide the graft towards the recipient bed.

In group 1, a small bleed with autologous serum from the scleral bed was used to adhere the graft to the recipient site. Sometimes a small blood vessel in the scleral bed was punctured for autologous serum. The conjunctival autologous graft was kept at the recipient scleral bed and gently pressed with a spatula; the edges of the graft were pinched with toothed forceps to the surrounding conjunctiva. The adhesion of the graft was ensured by moving the graft slightly. Then it was padded and bandaged for 18 hours-20 hours till the patient came for follow up the next day.

In group 2, the conjunctival graft was kept in place and 8-0 vicryl suture was applied, $1^{\text {st }}$ at two limbal edges and then sutured as needed and eye was pad and bandaged till they were followed up the next day.

Time taken for the surgery and intraoperative and postoperative complications were noted.
Patients were started on antibiotics-steroid eye drops on the next day and were tapered gradually.

The postoperative symptoms were assessed by a preformed questionnaire including grading of symptoms for pain, foreign body sensation and photophobia. It was scored as 0 to $3(0=$ Nothing; 1 = mild; 2 = moderate; $3=$ severe) and a mean score was given for each symptom in each group (Elwan, 2014).

The mean score was calculated and the result was analyzed statistically using one way Anova.

The overall satisfaction score was recorded at 6 weeks follow up as four grades: $0=$ unsatisfied; 1 = low satisfaction; $2=$ moderate satisfaction; $3=$ high satisfaction (Elwan, 2014). The data was analysed using Fischer's exact test.

Recurrences were observed during follow up and defined as encroachment of fibro-vascular connective tissue across the limbus and onto the cornea for any distance (Hirst et al., 1994).

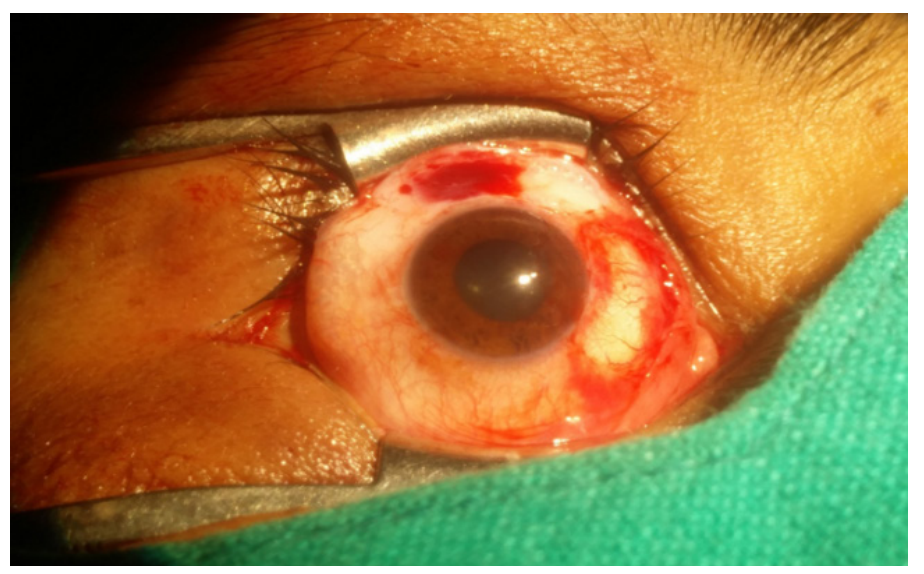

Figure 1: Postoperative clinical photograph showing sutureless conjunctival autograft. 

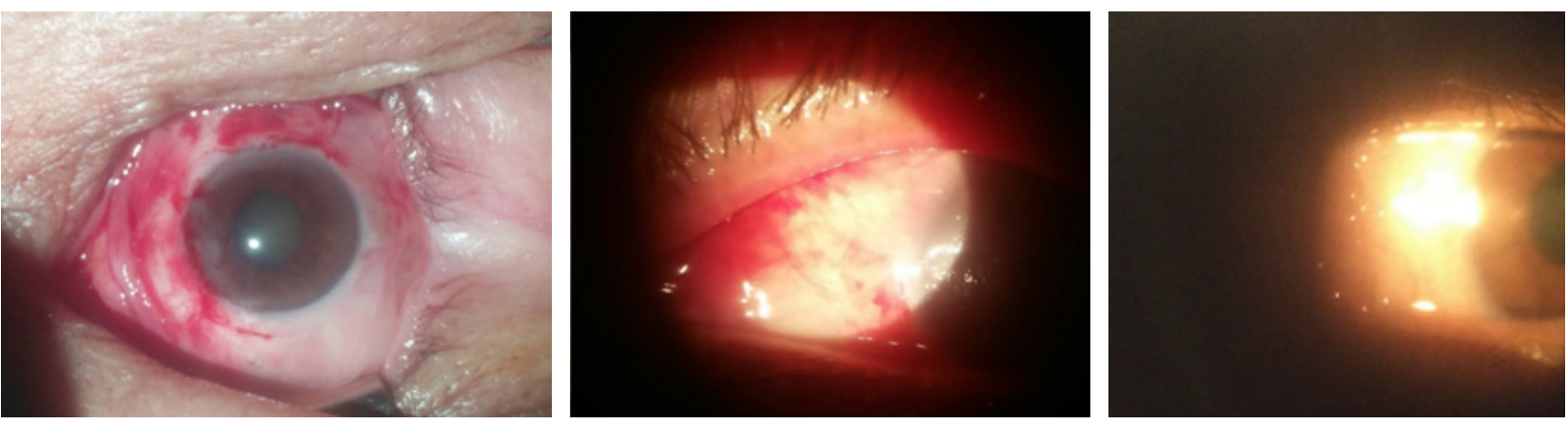

Figure 2 : Clinical photograph showing graft uptake at (from left to right) immediate, 2 weeks and 6 weeks post-surgery.

\section{RESULTS}

100 eyes of 100 patients were included in the study. 50 underwent sutureless glue free conjunctival autograft and 50 underwent sutured conjunctival autograft. Nasal pterygium was present in all cases. There were 55 female and 45 male in the study. 56 pterygia were present on the right side.

The mean age was $46.76 \pm 11.97$ years (group 1) and $47.24 \pm 12.76$ years (group 2) which was not significant statistically $(\mathrm{p}>0.05$ )
The time taken for surgery in group 1 was 20.18 \pm 2.08 minutes and $22.14 \pm 1.79$ minutes in group $2(\mathrm{p}<0.001)$.

In the sutureless group, postoperatively, 2 (4\%) eyes had graft dehiscence, which was due to rubbing of the eyes after opening the dressing on day 1. Autograft was re-sutured in these cases on the next day. 3(6\%) eyes had graft haemorrhage; these were seen in cases where vessels were punctured intentionally during surgery for better adhesion of graft.

Table 1: Demographic profile of study population.

\begin{tabular}{|l|c|c|}
\hline & Group 1 (N=50) & Group 2 (N=50) \\
\hline Mean age & $46.76 \pm 11.97$ & $47.24 \pm 12.76$ \\
\hline Gender & $42 \%(\mathrm{n}=21)$ & $48 \%(\mathrm{n}=24)$ \\
\hline Male & $58 \%(\mathrm{n}=29)$ & $52 \%(\mathrm{n}=26)$ \\
\hline Female & $58 \%(\mathrm{n}=29)$ & $54 \%(\mathrm{n}=27)$ \\
\hline Laterality & $42 \%(\mathrm{n}=21)$ & $46 \%(\mathrm{n}=23)$ \\
\hline Right &
\end{tabular}


At the 2nd week of follow-up, graft oedema was seen in $4(8 \%)$ cases, which resolved later. $4(8 \%)$ cases had graft retraction which was due to oedema. At 6 weeks follow up $1(2 \%)$ eye had granuloma at the area of exposed Tenon which was excised.

In the sutured group, there was no graft dehiscence. On day 1, $3(6 \%)$ eyes had graft haemorrhage, which was present due to suturing and trauma to vessels. At week 2, 1 (2\%) case had dellen which was treated with removal of suture and lubricants. 1(2\%) cases had graft retraction due to oedema which resolved at 6 weeks follow-up. 1 ( $2 \%)$ eye had foreign body granuloma which was excised.

The postoperative complication in either group was not statistically significant. Other postoperative complications such as scleral necrosis, graft necrosis or scleral thinning were not detected.

Table 2: Post-surgical complications.

\begin{tabular}{|l|c|c|c|c|}
\hline \multirow{2}{*}{\multicolumn{1}{c|}{ Complication }} & \multicolumn{2}{c|}{ Group 1 } & \multicolumn{2}{c|}{ Group 2 } \\
\cline { 2 - 5 } & Number & Percentage & Number & Percentage \\
\hline Graft hemorrhage & 3 & $6 \%$ & 3 & $6 \%$ \\
\hline Granuloma & 1 & $2 \%$ & 1 & $2 \%$ \\
\hline Dellen & 0 & $0 \%$ & 1 & $2 \%$ \\
\hline Graft retraction & 4 & $8 \%$ & 1 & $2 \%$ \\
\hline Graft dehiscence & 2 & $4 \%$ & 0 & $0 \%$ \\
\hline Conjunctival edema & 4 & $8 \%$ & 1 & $2 \%$ \\
\hline Graft necrosis & 0 & $0 \%$ & 0 & $0 \%$ \\
\hline Scleral necrosis & 0 & $0 \%$ & 0 & $0 \%$ \\
\hline Scleral thinning & 0 & $0 \%$ & 0 & $0 \%$ \\
\hline
\end{tabular}
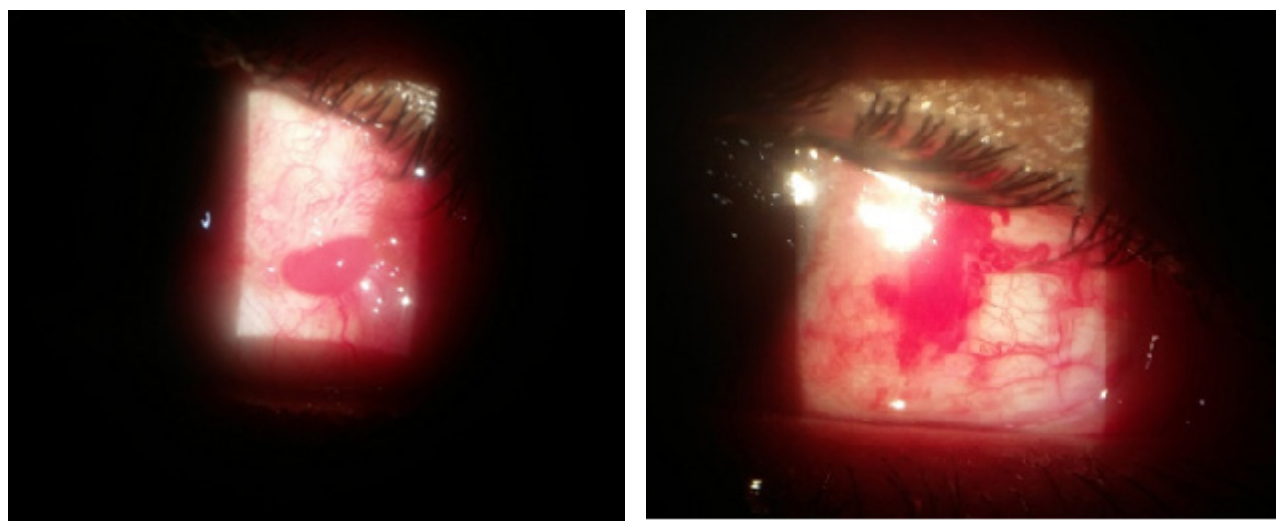

Figure 3: Complications: Suture granuloma (right), early subconjunctival hemorrhage in sutureless group (left). 
Table 3: Mean score for postoperative symptoms.

\begin{tabular}{|l|c|c|c|c|c|c|}
\hline \multirow{2}{*}{\multicolumn{1}{c|}{$\begin{array}{c}\text { Postoperative } \\
\text { symptoms }\end{array}$}} & \multicolumn{2}{c|}{ Day 1 } & \multicolumn{2}{c|}{ Day 14 } & \multicolumn{2}{c|}{ Day 42 } \\
\cline { 2 - 7 } & Group 1 & Group 2 & Group 1 & Group 2 & Group 1 & Group 2 \\
\hline Pain & 1.14 & 1.62 & 0.22 & 0.52 & 0 & 0.14 \\
\hline Foreign body sensation & 1.16 & 1.68 & 0.38 & 0.76 & 0.04 & 0.18 \\
\hline Photophobia & 0.64 & 1.22 & 0.66 & 0.22 & 0 & 0 \\
\hline
\end{tabular}

Table 4: Postoperative satisfaction score.

\begin{tabular}{|l|c|c|}
\hline & Group 1 & Group 2 \\
\hline Unsatisfied & 0 & 0 \\
\hline Low satisfaction & 6 & 1 \\
\hline Moderate satisfaction & 28 & 49 \\
\hline High Satisfaction & 16 & 0 \\
\hline
\end{tabular}

Postoperatively, the mean score was noted for pain, foreign body sensation and photophobia (Table 3). On day 1, mean score for pain was 1.14 , foreign body sensation was 1.16 , and photophobia was 0.64 in group 1 . In group 2, mean score for pain was 1.62 , foreign body sensation was 1.68 and photophobia was 1.22; ( $p$ value $<0.001$ ).

At week 2, in group 1, mean pain score was 0.22 , foreign body sensation was 0.38 and photophobia was 0.06 . In group 2 , mean pain score was 0.52 , foreign body sensation was 0.76 and photophobia was $0.22(\mathrm{p}<0.05)$.

At week 6, mean pain score was 0 in group 1 and 0.14 in group $2(p<0.05)$, foreign body sensation was 0.04 in group 1 and 0.18 in group 2 $(p>0.05)$. None of the patients had photophobia at $6^{\text {th }}$ week in both the groups.
At 6 weeks, the patient satisfaction score was statistically significant for group $1(p<0.001)$.

Gain in visual acuity in both the groups was not clinically significant.

There was no recurrence in either group till 6 weeks of follow up. At 1 year of follow-up, 4 eyes ( $8 \%$ ) in-group 1 and 5 eyes $(10 \%)$ in group 2 had recurrence which was statistically not significant between groups.

\section{DISCUSSION}

Several surgical techniques from simple excision leaving bare sclera to conjunctival limbal autograft are explained for the management of pterygium. Pterygium recurrence following primary pterygium surgery with bare sclera technique is around six times higher than with conjunctival 


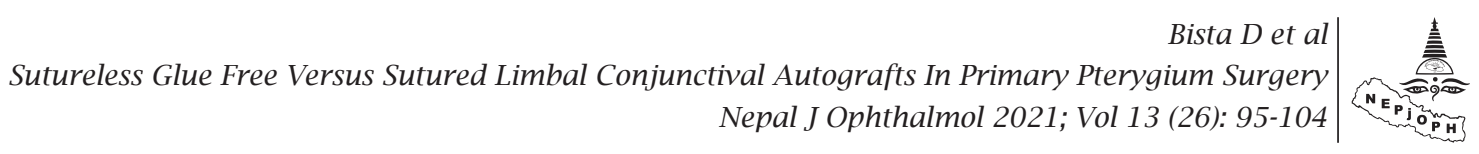

autograft placement (Sánchez-Thorin et al., 1998). Ma et al (2000) explained that the proliferation of subconjunctival fibroblasts and vascular cells was due to surgical trauma and subsequent postoperative inflammation. The deposited proteins further contribute to pterygium recurrence. Techniques have been developed to lower recurrences by using limbal conjunctival autograft and also by using adjunctive therapies like Mitomycin C, beta irradiation, 5-fluorouracil (Frucht-Pery and Ilsar, 1994; Salman and Mansour, 2011). Limbal auto-grafts can act as a barrier against conjunctival invasion onto the cornea and also supply stem cells of the corneal epithelium (Salman and Mansour, 2011).

In autologous conjunctival graft technique, the graft can be adhered to the bare sclera by sutures, fibrin glue or autologous fibrin from the scleral bed. (Gröner, 2008). Sutureless technique either with fibrin glue or autologous fibrin can have less discomfort than sutured technique when securing the graft.(Elwan, 2014; Yan et al., 2019; Yüksel et al., 2010) Fibrin glue which is used as an alternative to sutures for adhesion of the autologous graft, decreases postoperative pain and shorten the surgery time. (Koranyi et al., 2005). However, cost of the product has always been a factor limiting its use (Yüksel et al., 2010) Plasma derived products have been shown to have viral contaminants mostly hepatitis virus, Parvovirus B19 and prions despite inactivation. (Gröner, 2008) This leads to threat of spread of infection using the fibrin glue.
Sutureless glue-free technique has fewer postoperative complaints and no risk of disease transmission as with fibrin glue. (Sati et al., 2014; Sharma et al., 2015).

In this study, demographic profiles of cases are not significant. The age group included in the study is comparable to the age group in different studies. (Elwan, 2014; Sharma et al., 2015)

In our study, the mean surgical time for sutureless technique was $20.18 \pm 2.08$ minutes which was less as compared to sutured technique ( $22.14 \pm 1.79$ minutes); $(\mathrm{p}<0.001)$. The time taken for surgery is comparable and even faster in group 1. This was similar to other studies where sutureless technique required lesser time for surgery.(Elwan, 2014; Sati et al., 2014)

Graft dehiscence is a common complication in sutureless surgery mostly when fibrin glue is used. Alireza et al (2011) described the rate of dehiscence to be $13.3 \%$ when autologous fibrin was used to adhere the graft and attributed the cause to low levels of thrombin and fibrinogen. In our study, 2 (4\%) eyes in group 1 had graft dehiscence, which was due to rubbing of eyes. It presented as an early complication and the autograft was re-sutured. There was no graft dehiscence in-group 2. Our study had lesser dehiscence than a study done by Elwan (2014) where $8 \%$ cases had graft dehiscence in the sutureless group. Its incidence was low in the sutureless group $(1.3 \%)$ in a study done by Huda and Khaleque, (2019). 
Graft oedema was seen in 4(8\%) cases in group 1 and $1(2 \%)$ case in group 2 . It was not present in cases where the autograft was punctured intentionally and was also lesser in group 2 . This could be due to escape of fluid from the punctured site during suturing. In a study by Elwan (2014) it was present in $16 \%$ in group 1 and 6\%in group 2, which is more than our case. It was present in $8 \%$ in group 1 and $12 \%$ in group 2 in a study by Sharma et al(2015) which is different from our study. It resolved spontaneously within 6 weeks of surgery and required no intervention.

At second week 4(8\%)case in the sutureless group and $1(2 \%)$ in the sutured group had graft retraction which resolved at 6 weeks follow up and was due to graft oedema. It was less than the cases described by Elwan, (2014) where $12 \%$ cases in sutureless and $6 \%$ cases in sutured groups had graft retraction. Alireza et al., (2011) reported $20 \%$ of cases with graft retraction in a sutureless group. Only 3.9\%cases in sutureless and $4 \%$ cases in sutured groups had retraction in a study done by Huda and Khaleque, (2019).

One $(2 \%)$ eye in each group had granuloma, it was in the area where Tenon was exposed in group 1 and foreign body granuloma was present in group 2. Excision of granuloma was done in both cases. The mean score for postoperative symptoms; pain, foreign body sensation and photophobia were less in group 1 than in group 2. The symptoms were reported more severe in group 2 on day 1 and 14 but later at 6 weeks it was similar to group 1 (Table 3). This is similar to a study conducted by Elwan, (2014) where he reported lower postoperative symptoms in sutureless groups than with sutures. Postoperative symptoms were reported to be lesser in the sutureless group in many studies (Sati et al., 2014; Sharma et al., 2015; Yan et al., 2019).

In our study, the patient satisfaction score was significantly higher in group $1(p<0.001)$ (Table 4) which is comparable to a study by Elwan, (2014).

The recurrence at one year of follow-up was $8 \%$ in-group 1 and $10 \%$ in group 2, which was clinically not significant. Similarly shown in a study by Elwan (2014) where the recurrence rate was $6 \%$ in the sutureless group, and $8 \%$ in the sutured group taken after three months. Sharma et al., (2015) showed a lower recurrence rate for both techniques- $0 \%$ for sutureless and $4 \%$ for sutured. Longer follow up and larger sample size would give us better information on the recurrence.

\section{CONCLUSION}

Sutureless and glue-free conjunctival autograft surgery has fewer postoperative complaints and better patient satisfaction than sutured conjunctival autograft. The postoperative complications and recurrence of both techniques were comparable. 


\section{Limitation}

The size and grading of pterygium was not included in the study, which could have affected the recurrence of pterygium after surgery. Larger sample size and longer follow-up is required for more accurate conclusions.

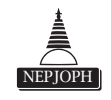

\section{REFERENCES}

Alireza F, Fariba B, Jafar GM, Peyman E, Naser A, Hamed S, et al. (2011). Efficacy of autologous fibrin glue for primary pterygium surgery with conjunctival autograft. Journal of Current Ophthalmology;23:39-47.

Avisar R, Arnon A, Avisar E, Weinberger D (2001). Primary pterygium recurrence time. Isr Med Assoc J;3:836-7.

Elwan SA (2014). Comparison between sutureless and glue free versus sutured limbal conjunctival autograft in primary pterygium surgery. Saudi J Ophthalmol;28:292-8. doi: 10.1016/j.sjopt.2014.03.012; PMid:25473346

Frucht-Pery J, Ilsar M (1994). The use of low-dose Mitomycin C for prevention of recurrent pterygium. Ophthalmology;101:759-62. doi: 10.1016/S0161-6420(94)31269-3.

Gröner A (2008). Pathogen safety of plasma-derived products - Haemate ${ }^{\circledR}$ P/Humate-P®. Haemophilia;14:54-71. doi: 10.1111/j.1365-2516.2008.01852.x; PMid:18786011.

Hill JC, Maske R (1989). Pathogenesis of pterygium. Eye;3( Pt 2):218-26. doi: 10.1038/eye.1989.31; PMid:2695353.

Hirst LW, Sebban A, Chant D (1994). Pterygium Recurrence Time. Ophthalmology;101:755-8. doi: 10.1016/S01616420(94)31270-X.

Huda MMU, Khaleque SA (2019). Comparison between Sutureless and Glue Free versus Sutured Limbal Conjunctival Autograft in Primary Pterygium Surgery. Medicine Today;31:1-8. doi: 10.3329/medtoday.v31i1.40313.

Kawasaki S, Uno T, Shimamura I, Ohashi Y (2003). Outcome of surgery for recurrent pterygium using intraoperative application of mitomycin C and amniotic membrane transplantation. Jpn J Ophthalmol;47:625-6. doi: 10.1016/j. jjo.2003.09.011

Koranyi G, Seregard S, Kopp ED (2005). The cut-and-paste method for primary pterygium surgery: long-term followup. Acta Ophthalmol. Scand;83:298-301. doi: 10.1111/j.1600-0420.2005.00465.x

Koranyi G, Seregard S, Kopp ED (2004). Cut and paste: a no suture, small incision approach to pterygium surgery. Br J Ophthalmol;88:911-4. doi: 10.1136/bjo.2003.032854; PMid:15948780

Lam DSC, Wong AKK, Fan DSP, Chew S, Kwok PSK, Tso MOM (1998). Intraoperative mitomycin C to prevent recurrence of pterygium after excision: A 30-month follow-up study. Ophthalmology;105:901-5. doi: 10.1016/ S0161-6420(98)95034-5 
Monselise M, Schwartz M, Politi F, Barishak YR (1984). Pterygium and Beta Irradiation. Acta Ophthalmol. (Copenh.);62:315-9. doi: 10.1111/j.1755-3768.1984.tb08408.x; PMid:6426246

Salman AG, Mansour DE (2011). The recurrence of pterygium after different modalities of surgical treatment. Saudi J Ophthalmol;25:411-5. doi: 10.1016/j.sjopt.2010.10.013; PMid:23960956

Sánchez-Thorin JC, Rocha G, Yelin JB (1998). Meta-analysis on the recurrence rates after bare sclera resection with and without mitomycin $\mathrm{C}$ use and conjunctival autograft placement in surgery for primary pterygium. $\mathrm{Br} \mathrm{J}$ Ophthalmol;82:661-5. doi: 10.1136/bjo.82.6.661; PMid:9797669

Sati A, Shankar S, Jha A, Kalra D, Mishra S, Gurunadh VS (2014). Comparison of efficacy of three surgical methods of conjunctival autograft fixation in the treatment of pterygium. Int Ophthalmol;34:1233-9. doi: 10.1007/s10792014-0013-y; PMid:25374052

Sharma A, Raj H, Gupta A, Raina AV (2015). Sutureless and glue-free versus sutures for limbal conjunctival autografting in primary pterygium surgery: A prospective comparative study. J Clin Diagn Res;9:NC06. PMid:26675383

Yan B, Peng L, Peng H, Zhou S, Chen B (2019). Modified Sutureless and Glue-Free Method Versus Conventional Sutures for Conjunctival Autograft Fixation in Primary Pterygium Surgery: A Randomized Controlled Trial. Cornea;38:1351-7. doi: 10.1097/ICO.0000000000002137; PMid:31490271

Youngson RM (1972). Recurrence of pterygium after excision. Br. J. Ophthalmol;56:120-5. PMid:5010313

Yüksel B, Ūnsal SK, Onat S (2010). Comparison of fibrin glue and suture technique in pterygium surgery performed with limbal autograft. Int J Ophthalmol;3:316-20. doi: 10.3980/j.issn.2222-3959.2010.04.09 